\title{
GESTANTES INFECTADAS PELO HIV-1 ATENDIDAS EM SERVIÇO DE REFERÊNCIA: CARACTERÍSTICAS CLÍNICAS E SOCIODEMOGRÁFICAS
}

\author{
HIV-INFECTED PREGNANT WOMEN ATTENDING REFERENCE SERVICE: \\ CLINICAL AND SOCIODEMOGRAPHIC FEATURES
}

\author{
Ana Teresa Mancini Pimenta ${ }^{a^{*}}$, Geraldo Duarte ${ }^{b^{*}}$, José Carlos Couto-Fernandez ${ }^{\mathrm{c}^{* *}}$, \\ Isadora Alonso Correa ${ }^{\mathrm{d}^{* * *}}$, Patricia Pereira dos Santos Melli ${ }^{*}$, Silvana Maria Quintana ${ }^{\mathrm{f}^{*}}$ \\ aanateresa@usp.br, bgduarte@fmrp.usp.br, 'coutofer@ioc.fiocruz.br, disadora.alonso@ioc.fiocruz.br, emelli@netsite.com.br, fquintana@fmrp.usp.br \\ *Universidade de São Paulo - São Paulo (SP), Brasil \\ **Fundação Oswaldo Cruz-IOC/FIOCRUZ - Rio de Janeiro (RJ)
}

Data de recebimento do artigo: 01/05/2014

Data de aceite do artigo: 05/01/2015

\section{RESUMO}

Introdução: É importante identificar características de gestantes infectadas pelo HIV, para elaborar açôes de melhoria da assistência a essas mulheres. Objetivo: $\mathrm{O}$ objetivo do estudo foi caracterizar as gestantes infectadas pelo vírus da imunodeficiência humana (HIV), atendidas em ambulatório de moléstias infectocontagiosas em obstetrícia, no município de Ribeirão Preto (SP). Materiais e métodos: Foi realizado um estudo do tipo corte transversal, no período de 2010 a 2012, utilizando dados secundários de prontuários médicos. Resultados: Foram incluídas 113 gestantes infectadas pelo HIV, com média de idade de 28,9 anos, maioria branca $(62,8 \%)$, casada ou amasiada $(71,7 \%)$, e a escolaridade de $31,9 \%$ variava entre 9 e 11 anos. Observou-se diagnóstico da infecção pelo HIV durante exames de pré-natal da maioria das mulheres, início tardio do pré-natal e maioria assintomática. A intercorrência mais comum durante a gravidez foi anemia. $60 \%$ das gestantes tiveram boa adesão ao uso de terapia antirretroviral, enquanto $58,7 \%$ delas apresentou carga viral indetectável, próximo à $34^{\mathrm{a}}$ semana de gestaçâo. 29,8\% apresentaram carga viral acima de 1.000 cópias $/ \mathrm{mL}$. O parto de $82,5 \%$ das mulheres foi realizado com idade gestacional acima de 37 semanas; o tipo de parto em 51\% foi cesárea. Conclusóes: os resultados mostraram que houve predomínio de gestantes infectadas pelo HIV na faixa etária de 25 a 34 anos, assintomáticas e com diagnóstico de infecção pelo vírus devido a exames de pré-natal.

Palavras-chave: Gestantes; HIV-1; cuidado pré-natal; saúde materno-infantil.

\section{ABSTRACT}

Introduction: It is important to identify features of HIV-infected pregnant women, to develop actions to improve assistance for these women. Objective: The purpose of this study was to describe pregnant women infected with human immunodeficiency virus (HIV), attended at outpatient clinic of infectious disease in obstetrics in Ribeirão Preto (SP). Materials and methods: It was performed a cross-sectional study during the period 2010-2012, using secondary data from medical records. Results: It were included 113 pregnant women with HIV infection with an average age of 28.9 years, most of them were white $(62.8 \%)$, married or cohabitating $(71.7 \%)$, and formal education of $31.9 \%$ were between 9 and 11 years. Was observed that diagnosis of HIV infection of most women occurred during prenatal exams, late onset of prenatal care, and majority were asymptomatic. The most frequent complication during pregnancy was anemia. Good adherence to antiretroviral therapy was observed for $60.0 \%$ of pregnant women. While $58.7 \%$ of them presented undetectable viral load around the $34^{\text {th }}$ week of gestation, $29.8 \%$ presented viral load above 1,000 copies $/ \mathrm{mL}$. Delivery of $82.5 \%$ of women was carried out with a gestational age over 37 weeks; the mode of delivery of $51.0 \%$ was cesarean section. Conclusions: The results show predominance of HIV-infected pregnant women in the age group 25-34 years old; most were asymptomatic and had diagnosis of HIV infection due to antenatal tests.

Keywords: Pregnant women; HIV-1; prenatal care; maternal; child health. 


\section{Introdução}

Ao longo dos trinta anos da história da síndrome de imunodeficiência adquirida (AIDS) no Brasil, a epidemia apresentou alteraçóes nas características epidemiológicas. Na década de 1980, a infecção pelo vírus da imunodeficiência humana (HIV) era predominante em homens que faziam sexo com homens de nível socioeconômico elevado, que residiam em metrópoles. A partir da década de 1990, ocorreu o aumento no número de casos da doença entre usuários de drogas injetáveis, seguido do aumento de casos em homens heterossexuais e mulheres ${ }^{1}$. Observou-se a interiorização, pauperização e feminização da epidemia, evidenciando a disseminação da infecção por HIV para municípios menores e com renda per capita mais baixa ${ }^{2}$, aumento do número de casos em pessoas com baixa escolaridade ${ }^{3}$ e maior vulnerabilidade das mulheres à infecção pelo vírus ${ }^{4}$. Esta vulnerabilidade fica evidente ao avaliarmos a razão homens/mulheres, que em 1983 era de 38 casos de AIDS no sexo masculino para um caso no sexo feminino; em 2010 foi 1,6 caso no sexo masculino para um caso no sexo feminino 5 . A taxa de prevalência da infecçáo pelo HIV em mulheres de faixa etária entre 15 e 49 anos é de 0,41\% ${ }^{6}$. Em 2011, no Estado de São Paulo, foram diagnosticados 2.775 casos em mulheres ${ }^{5}$. Somado a esse número, 1.280 gestantes foram notificadas como infectadas pelo vírus?

$\mathrm{O}$ avanço da infecção pelo HIV entre mulheres, principalmente em idade reprodutiva, causou o aumento de casos em crianças decorrentes da transmissão vertical do vírus ${ }^{8}$. A transmissão materno-infantil pode acontecer durante a gestação ou parto, e também após o nascimento da criança, por meio da amamentação", ${ }^{10}$. Contudo, $75 \%$ dos casos referem-se à transmissão intraparto ${ }^{11}$. Entre os fatores associados à transmissão vertical, destacam-se: carga viral elevada no plasma; trato genital e leite materno ${ }^{12}$; baixa contagem de linfócitos $\mathrm{T}$ CD4+; comorbidades infecciosas e obstétricas ${ }^{13}$; e parto vaginal ${ }^{14}$.

De acordo com a Política Nacional de Atenção Integral à Saúde da Mulher, a situação socioeconômica da população feminina, bem como a diversidade dos municípios e Estados, devem ser consideradas na formulação de políticas públicas associadas à integralidade e promoção da saúde da mulher ${ }^{15}$.

A finalidade deste estudo foi caracterizar as gestantes infectadas pelo HIV atendidas em serviço de referência de Ribeirão Preto (SP), para assistência ao ciclo gravídico puerperal. Acredita-se que, identificando características desta população, seja possível elaborar açóes de melhoria de assistência a essas mulheres.

\section{Materiais e métodos}

O estudo do tipo corte transversal foi realizado no Ambulatório de Moléstias Infectocontagiosas em Ginecologia e Obstetrícia do Hospital das Clínicas da Faculdade de Medicina de Ribeirão Preto da Universidade de São Paulo (USP), no período de 2010 a 2012. Este ambulatório é serviço de referência de assistência ao ciclo gravídico puerperal para os 26 municípios pertencentes à Direção Regional de Saúde XIII (Ribeirão Preto). Foram incluídas 113 gestantes infectadas pelo HIV, que assinaram o Termo de Consentimento Livre e Esclarecido (TCLE). Os dados das 113 pacientes foram coletados de prontuários médicos e incluíram informaçôes pessoais e obstétricas sobre a infecçáo pelo HIV, além de dados clínicos e laboratoriais. Eles foram inseridos no programa Excel e analisados por meio de estatística descritiva. As variáveis foram apresentadas em tabelas e gráficos, e expressas em proporçôes, medidas de tendência central e dispersão. $\mathrm{O}$ projeto de pesquisa de um estudo maior do qual foi derivado este artigo foi aprovado pelo Comitê de Ética em Pesquisa do Hospital das Clínicas da Faculdade de Medicina de Ribeirão Preto da USP (processo ${ }^{\circ} 13411 / 2009$ ).

\section{Resultados}

Neste estudo, a média de idade das gestantes foi de 28,9 anos (15-43 anos; $\mathrm{dp} \pm 6,0)$, com predominância na faixa etária de 25 a 34 anos (Tabela 1). A maioria das mulheres é branca $(62,8 \%)$, apresentava escolaridade entre 9 e 11 anos (31,9\%), casada ou amasiada $(71,7 \%)$, não ingeria bebidas alcoólicas $(77,9 \%)$, não fumava $(64,6 \%)$ e não usava ou havia usado drogas ilícitas $(66,4 \%)$. Observou-se o inicio do pré-natal de $72,6 \%$ das gestantes no $2^{\circ}$ e $3^{\circ}$ trimestre gestacional.

O diagnóstico de infecção pelo HIV de 39,8\% das mulheres havia ocorrido na gestação em curso. $\mathrm{O}$ diagnóstico das demais gestantes havia acontecido, em média, há 6,5 anos $(\mathrm{dp} \pm 4,1)$ antes da gestação em curso, e $60,3 \%$ delas receberam o diagnóstico em outra gravidez. No total, $76,1 \%$ das mulheres receberam o diagnóstico de infecção pelo vírus devido a exames realizados durante o pré-natal. A categoria mais provável de exposiçáo ao HIV de $96,5 \%$ das gestantes foi a heterossexual.

Dentre as gestantes, $52(46,0 \%)$ nunca haviam utilizado antirretrovirais. Entre aquelas com uso prévio deste medicamento, $16,4 \%$ havia utilizado três ou mais esquemas; $26,2 \%$ havia utilizado dois esquemas e $57,4 \%$, apenas um esquema. A combinação zidovudina + lamivudina + lopinavir/ritonavir já havia sido utilizada por 32,8\% das gestantes; a combinação zidovudina + lamivudina+nelfinavir foi utilizada por $26,2 \%$ delas, e apenas $6,8 \%$ havia utilizado algum esquema contendo nevirapina. 
Tabela 1: Características sociodemográficas das gestantes infectadas pelo HIV atendidas em ambulatório de pré-natal, Ribeirão Preto - SP, 2010-2012.

\begin{tabular}{|c|c|c|}
\hline Características & $\mathbf{n}$ & $\%$ \\
\hline \multicolumn{3}{|l|}{ Idade (anos) } \\
\hline $15-19$ & 07 & 6,2 \\
\hline $20-24$ & 21 & 18,6 \\
\hline $25-29$ & 31 & 27,4 \\
\hline $30-34$ & 33 & 29,2 \\
\hline $35-39$ & 17 & 15,0 \\
\hline $40-44$ & 04 & 3,6 \\
\hline \multicolumn{3}{|l|}{ Cor } \\
\hline branca & 71 & 62,8 \\
\hline preta & 19 & 16,9 \\
\hline parda & 23 & 20,3 \\
\hline \multicolumn{3}{|l|}{ Escolaridade (anos) } \\
\hline analfabeta & 04 & 3,5 \\
\hline $0-4$ & 16 & 14,2 \\
\hline $5-8$ & 33 & 29,2 \\
\hline $9-11$ & 36 & 31,9 \\
\hline$>12$ & 06 & 5,3 \\
\hline Sem informação & 18 & 15,9 \\
\hline \multicolumn{3}{|l|}{ Estado marital } \\
\hline amasiada/ casada & 81 & 71,7 \\
\hline solteira & 27 & 23,9 \\
\hline desquitada & 05 & 4,4 \\
\hline Alcoolismo & 25 & 22,1 \\
\hline Tabagismo & 40 & 35,4 \\
\hline Uso de drogas ilícitas & 38 & 33,6 \\
\hline
\end{tabular}

O parceiro de $31,0 \%$ das mulheres também era infectado pelo HIV. A média de gestaçóes foi 3,6 $(\mathrm{dp} \pm 2,2)$, enquanto a média de partos foi $2(\mathrm{dp} \pm 2,0)$, e de aborto foi $0(\mathrm{dp} \pm 0,6)$.

O estágio da infecçáo pelo HIV, de acordo com o Center for Disease Control and Prevention, de 69,0\% das gestantes era A1 e A2; 5,3\% estava no estágio C3 (Figura 1).

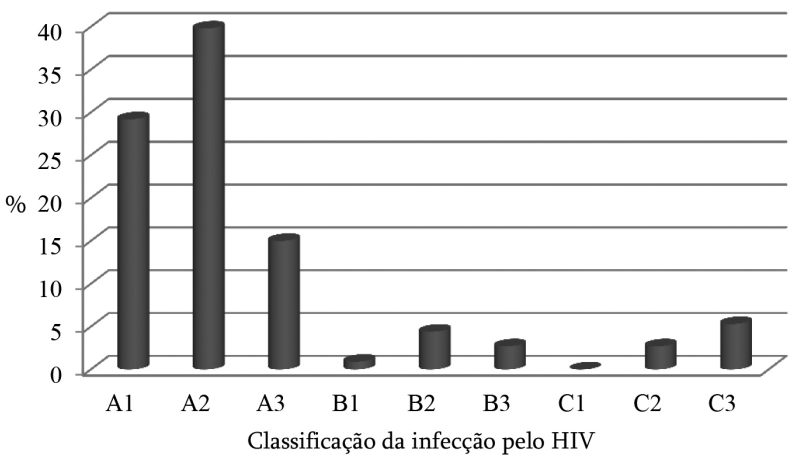

Figura 1: Classificação da infecção pelo HIV (CDC) das 113 gestantes, Ribeirão Preto-SP, 2010-2012.
Dezesseis mulheres $(14,2 \%)$ já haviam apresentado alguma infecção oportunista antes da gestação em curso. O mais comum foi a candidíase oral $(31,25 \%)$, seguida de neoplasia intraepitelial cervical (NIC) graus 2 ou $3(18,75 \%)$, e tuberculose (18,75\%).

A carga viral das gestantes no início do pré-natal no ambulatório variou de indetectável ( $<50$ cópias $/ \mathrm{mL}$ ) a 323.319 cópias $/ \mathrm{mL}$, mediana de 5.795 cópias $/ \mathrm{mL}$. A maioria das mulheres apresentou contagem de linfócitos T CD4 entre 200 e 499 células $/ \mathrm{mm}^{3}$, e a média da contagem de linfócitos T CD8 foi de 823 células $/ \mathrm{mm}^{3}$.

Tabela 2: Quantificação da carga viral, linfócitos T CD4+ e linfócitos T CD8+ em gestantes infectadas pelo HIV atendidas em ambulatório de pré-natal, Ribeirão Preto - SP, 2010-2012.

\begin{tabular}{|c|c|c|}
\hline Quantificaçáo & n & $\%$ \\
\hline \multicolumn{3}{|l|}{ Carga viral: cópias/mL } \\
\hline$<50-999$ & 29 & 25,6 \\
\hline $1.000-9.999$ & 45 & 39,8 \\
\hline 10.000-99.999 & 29 & 25,6 \\
\hline$>100.000$ & 4 & 3,7 \\
\hline sem informação & 6 & 5,3 \\
\hline \multicolumn{3}{|l|}{ T CD4: cél./. $\mathrm{mm}^{3}$} \\
\hline$<200$ & 14 & 12,4 \\
\hline $200-499$ & 53 & 46,9 \\
\hline$>500$ & 41 & 36,3 \\
\hline sem informação & 5 & 4,4 \\
\hline T CD8: cél. $/ \mathrm{mm}^{3}$, média & 823 & \\
\hline
\end{tabular}

A principal intercorrência durante a gestaçâo foi a anemia, seguida de candidíase vaginal (Tabela 3).

Tabela 3: Intercorrências durante a gestação de mulheres infectadas pelo HIV atendidas em ambulatório de pré-natal, Ribeirão Preto - SP, 2010-2012.

\begin{tabular}{lcc}
\hline Intercorrências & n & $\%$ \\
\hline Anemia & 32 & 28,3 \\
Candidíase vaginal & 28 & 24,8 \\
Dislipidemia & 27 & 23,9 \\
Condilomatose/ NIC1 & 16 & 14,2 \\
Infecção do trato urinário & 12 & 10,6 \\
Vaginose bacteriana & 11 & 9,7 \\
Tricomoníase & 6 & 5,3 \\
Sífilis & 6 & 5,3 \\
\hline
\end{tabular}

NIC $1=$ neoplasia intraepitelial de grau 1 .

Quanto ao uso da TARV, 60,0\% das gestantes apresentaram boa adesão. A quantificação da carga viral na $34^{a}$ semana de gestação mostrou que $58,7 \%$ das mulheres conseguiu indetecção do vírus ( $<50$ cópias $/ \mathrm{mL}$ ). No entanto, 29,8\% apresentavam carga viral acima de 
1.000 cópias. Quatro mulheres perderam seus fetos por abortamento espontâneo. O tipo de parto de 51,0\% das gestantes foi cesárea. A maioria das gestantes teve o parto realizado com idade gestacional acima de 37 semanas $(82,5 \%)$, e $9,3 \%$ com idade gestacional entre 36 e 37 semanas. Não foi verificado nenhum caso de transmissão vertical do HIV-1 em crianças de gestantes deste estudo.

\section{Discussão}

Neste estudo, a faixa etária predominante $(56,6 \%$ entre 25 e 34 anos) difere um pouco daquela encontrada em gestantes infectadas pelo HIV no Brasil de modo geral, concentrada na faixa etária de 20 a 29 anos. Quanto à escolaridade, os dados divulgados pelo Ministério da Saúde do Brasil apontam maior concentração na categoria de 5 a 8 anos 7 . Observa-se que na microrregiáo de Ribeirão Preto, a escolaridade, avaliada pelo indicador de educação do Índice de Desenvolvimento Humano (IDH), apresenta um dos valores mais elevados dentro do Estado de São Paulo ${ }^{16}$.

O diagnóstico de infecção pelo HIV da maioria das mulheres $(76,1 \%)$ foi realizado durante a gestação em curso ou anterior. Isso sugere que a realizaçáo de exames para o diagnóstico de infecção pelo HIV durante o pré-natal seja uma estratégia eficaz, tanto para a discriminação sorológica das mulheres, quanto para possibilitar medidas preventivas da transmissão vertical do vírus. Embora a avaliação pré-concepcional não seja $o$ momento ideal para rastreio das infecçôes, não há dúvidas de que a inserção do teste anti-HIV nos exames de pré-natal consiste em uma ferramenta essencial para prevenir a transmissão vertical, evitar a transmissão para parceiros sexuais e usuários de drogas, além de tratar adequadamente as mulheres infectadas. Porém, o início do pré-natal no $2^{\circ}$ e $3^{\circ}$ trimestre da gravidez, observado em $72,6 \%$ das gestantes, poderia comprometer o tempo de uso dos antirretrovirais. Sabe-se que o fator mais importante para a transmissão vertical do HIV é a carga viral materna, e o fato de iniciar o pré-natal em idade gestacional mais avançada implicaria em demora no início das medicações antirretrovirais e, consequentemente, na diminuição da carga viral. Além disso, o início tardio do pré-natal também pode prejudicar o diagnóstico e tratamento de infecçóes do trato urogenital, e de outras doenças sexualmente transmissíveis, fatores que são sabidamente associados à elevação da carga viral ${ }^{12,17}$.

A quantificação da carga viral em torno da $34^{a}$ semana de gestação auxilia na definição da via de parto, visto que a transmissão vertical é inferior a $1 \% \mathrm{em}$ pacientes em uso de antirretrovirais com carga viral abaixo de 1.000 cópias $/ \mathrm{mL}^{13}$. Dentre as gestantes, $29,8 \%$ apresentaram carga viral acima de 1.000 cópias $/ \mathrm{mL}$ na idade gestacional de 34 semanas. A não redução da carga viral pode acontecer por seguimento inadequado das recomendaçóes médicas com a não realização dos exames, ou a adesão inadequada ao uso de antirretrovirais observada em $40,0 \%$ das gestantes. Esses resultados indicam a necessidade de aprimoramento do diagnóstico precoce da infecção pelo HIV em gestantes, sendo incentivo ao início precoce do pré-natal e adesão às medidas profiláticas e terapêuticas. Apesar de isso depender de mudanças na cultura e educação da população. No entanto, o uso adequado dos antirretrovirais foi capaz de reduzir a carga viral das gestantes e aumentar a contagem de linfócitos T CD4+. Somado a isso, a boa qualidade do serviço de saúde na atençáo às gestantes foi fator crucial na ausência de transmissão vertical do HIV-1 observada nos recém-nascidos destas gestantes.

A intercorrência mais comum durante a gravidez foi de anemia em 28,3\% das gestantes, de acordo com a anotação nos prontuários médicos. A anemia é comum durante a gestação, no entanto, requer acompanhamento dos níveis de hemoglobina da mulher durante o pré-natal, além de suplementação de ferro e ácido fólico. Em gestantes infectadas pelo HIV, o uso da zidovudina é um risco em potencial para o desencadeamento da anemia materna ${ }^{10}$. A baixa contagem de linfócitos $\mathrm{T}$ CD4 está associada à anemia em gestantes infectadas pelo $\mathrm{HIV}^{18}$. Neste estudo, $12,9 \%$ das mulheres apresentaram contagens de células CD4 menores que 200 células $/ \mathrm{mm}^{3}$. Outros fatores de risco para a anemia são a presença de doenças oportunistas, presentes em 9,7\% das gestantes, e estágio avançado da infecção pelo $\mathrm{HIV}^{19}$, evidenciado como classificação $\mathrm{C} 3$ da infecção em $5,3 \%$ das gestantes.

A candidíase vaginal e vaginose bacteriana, observadas em respectivamente $24,8 \%$ e $9,7 \%$ das grávidas, são consideradas comuns durante a gestação, e devem ser tratadas com antibióticos apropriados ${ }^{13}$. Condilomatose e NIC I, diagnosticados em 14,2\% das gestantes, são consequência da infecção por subtipos do papilomavírus humano (HPV). Mulheres infectadas pelo HIV são mais propensas à aquisição, persistência e progressão de manifestações por $\mathrm{HPV}^{20,21}$. O risco da condilomatose em gestantes ocorre quando a doença não é tratada e o parto é vaginal. Desse modo, a exposiçáo e infecçáo do nascituro ao HPV pode ocasionar papilomatose laríngea recorrente. A tricomoníase tem maior proporçâo de casos entre mulheres infectadas pelo HIV e em gestantes. As implicações, incluem-se parto pré-termo e baixo peso ao nascer ${ }^{22}$. A sífilis apresenta risco de dano placentário e aumento de transmissão vertical do HIV intrauterino, além do risco da sífilis congênita ${ }^{13}$. A notificação de casos de sífilis na gestação aumentou em $166 \%$ no período de 
2006 a 2008 no estado de São Paulo, constituindo um desafio para a saúde pública, já que o objetivo é manter a taxa de casos de sífilis congênita abaixo de um em cada 1000 nascidos vivos ${ }^{8}$.

Eventos que ocasionam resposta inflamatória clínica ou subclínica local normalmente elevam os níveis de RNA viral nas secreçóes do trato genital, devido ao recrutamento e/ou ativação de células infectadas pelo HIV. Esse aumento de RNA viral no conteúdo vaginal independe dos níveis plasmáticos de RNA viral. A inflamação genital está associada com depleção de linfócitos $\mathrm{T}$ CD4+, tanto sistemicamente como no trato genital inferior ${ }^{17}$. O RNA viral pode ser detectado, às vezes, em números elevados de cópias no trato genital de mulheres em uso de HAART e carga viral plasmática indetectável. Em alguns casos, a carga viral plasmática é indetectável, e no trato genital a carga viral alcança valores de 480.000 a 640.000 cópias $/ \mathrm{mL}^{23}$. A presença de DST, associada à inflamação genital, que causa elevação dos níveis de HIV, aumenta o risco de transmissão da infecçãa ${ }^{17}$. Portanto, se as gestantes apresentam algum processo inflamatório genital, por exemplo vaginose, candidíase ou DST, e não realizam o tratamento adequado, mesmo com carga viral plasmática indetectável, ou chegam tardiamente ao pré-natal, há risco de transmissáo vertical do HIV quando for realizado o parto vaginal.

A dislipidemia acometeu $23,9 \%$ das gestantes, provavelmente devido ao uso da associação lopinavir/ ritonavir, que apresenta este distúrbio ${ }^{10}$, entre outros efeitos. Por outro lado, a dislipidemia materna é uma característica da gravidez, devido ao metabolismo alterado dos lipídios ${ }^{24}$. El Beitune et al. ${ }^{25}$ observaram o aumento de lipídeos ao longo da gestação em três grupos de gestantes. Houve aumento significativo dos níveis de LDL-colesterol apenas em gestantes infectadas pelo HIV em uso de antirretrovirais.

A infecção urinária durante a gestação, diagnosticada em 10,6\% das gestantes, resulta de bacteriúria assintomática associada a mudanças anatomofisiológicas no corpo da mulher. Essa infecção requer tratamento urgente, com o intuito de evitar complicaçôes perinatais ${ }^{26}$,como parto pré-termo, baixo peso ao nascer e sepse neonatal ${ }^{27}$.

Os resultados deste estudo apontaram o predomínio de gestantes infectadas pelo HIV na faixa etária de 25 a 34 anos, cor branca, baixa escolaridade e com vínculo conjugal. Além disso, a maioria das gestantes recebeu o diagnóstico de infecção pelo HIV devido a exames de pré-natal, era assintomática, que apresentava contagem de linfócitos T CD4+ entre 200 e 499 células $/ \mathrm{mm}^{3}$ e carga viral $\geq 1000$ cópias $/ \mathrm{mL}$. As intercorrências mais comuns durante o pré-natal foram anemia, candidíase vaginal e dislipidemia.

\section{Referências}

1. Barbosa Junior A, Szwarcwald CL, Pascom ARP, Souza Júnior PB. Tendências da epidemia de AIDS entre subgrupos sob maior risco no Brasil, 1980-2004. Cad Saúde Pública. 2009;25(4):727-37.

2. Brito AM, Castilho EA, Szwarcwald CL. AIDS e infecção pelo HIV no Brasil: uma epidemia multifacetada. Rev Soc Bras Med Trop. 2000;34(2):207-17.

3. Parker R, Camargo Jr KR. Pobreza e HIV/AIDS: aspectos antropológicos e sociológicos. Cad Saúde Pública 2000;16(sup. 1):S89-S102.

4. Fonseca MGP, Bastos FI. Twenty-five years of the AIDS epidemic in Brazil: principal epidemiological findings, 19802005. Cad Saúde Pública. 2007;23(suppl. 3):S333-S343.

5. Departamento de Informática do SUS. Epidemiológicas e morbidade. Brasília: 2012

6. Szwarcwald CL, Barbosa Júnior A, Souza-Júnior PRB, Lemos KRV, Frias PG, Luhm KR, et al. HIV testing during pregnancy: use of secondary data to estimate 2006 test coverage and prevalence in Brazil. Braz J Infect Dis. 2008;12(3):167-72.

7. Brasil. Ministério da Saúde. Boletim epidemiológico Aids e DST. Ano IX no 01. Secretaria de Vigilância em Saúde. Departamento de DST, Aids e Hepatites Virais [Internet]. Brasília: Ministério da Saúde; 2012. Disponível em: <http://www.aids.gov.br/sites/default/files/anexos/publicacao/2011/50652/boletim_aids_2011_final_m_pdf_26659. pdf $>$. [acesso em 10 jul. 2015].

8. Eliminação da transmissão vertical do HIV e da sífilis no Estado de São Paulo. Rev Saúde Pública. 2011;45(4):812-5.

9. Becquet R, Ekouevi DK, Arrive E, Stringer JSA, Meda N, Chaix ML, et al. Universal antiretroviral therapy for pregnant and breastfeeding HIV-1-infected women: towards the elimination of mother-to-child transmission of HIV-1 in resource limited settings. CID 2009;49:1936-45.

10. World Health Organization. Antiretroviral drugs for treating pregnant women and preventing HIV infection in infants: towards universal access: recommendations for a public health approach [Internet]. Geneva: World Health Organization;2010 [citado em 21 fev. 2012]. Disponível em: <http://whqlibdoc.who.int/publications/2010/9789241599818_eng.pdf>. [acesso em 10 jul. 2015].

11. Ehrnst A, Lindgren S, Dictor M, Johansson B, Sönnerborg A, Czajkowski J, et al. HIV in pregnant women and their offspring: evidence for late transmission. Lancet. 1991;338(8761): 203-7.

12. Kourtis AP, Bulterys M. Mother-to-child transmission of HIV: pathogenesis, mechanism and pathways. Clin Perinatol. 2010;37:721-37.

13. Brasil. Ministério da Saúde. Recomendaçôes para Profilaxia da Transmissão Vertical do HIV e Terapia Antirretroviral em Gestantes. Brasília: Secretaria de Vigilância em Saúde, 
Programa Nacional de DST e Aids. Brasília: Ministério da Saúde; 2010. (Séries Manuais no 46).

14. Landesman SH, Kalish LA, Burns DN, Minkoff H, Fox $\mathrm{HE}$, Zorilla C, et al. Obstetrical factors and the transmission of human immunodeficiency virus type 1 from mother to child. NEJM. 1996;334:1617-23.

15. Brasil. Ministério da Saúde. Política Nacional de Atenção Integral à Saúde da Mulher: princípios e diretrizes. Secretaria de Atenção à Saúde. Departamento de Açôes Programáticas e Estratégicas. Brasília: Ministério da Saúde; 2009.

16. Pimenta ATM, Rodrigues-Júnior AL, Ruffino-Netto A. Geoepidemiologia da comorbidade aids/tuberculose no Estado de São Paulo - Brasil - 1996 a 2005. Caminhos de Geografia. 2012;13(41):68-79.

17. Blish CA, McClelland RS, Richardson BA, Jaoko W, Mandaliya K, Baeten JM, et al. Genital inflammation predicts HIV-1 shedding independent of plasma viral load and systemic inflammation. J Acquir Immune Defic Syndr. 2012;61(4):436-40.

18. Ezechi OC, Kalejaiye OO, Gab-Okafor CV, Oladele DA, Oke B, Ekama SO, et al. The burden of anemia and associated factors in HIV positive Nigerian women. Arch Gynecol Obstet. 2013;287(2):239-44.

19. Sullivan PS, Hanson DL, Chu SY, Jones JL, Ward JW. Epidemiology of anemia in human immunodeficiency virus (HIV)-infected persons: results from the multistate adult and adolescent spectrum of HIV disease surveillance project. Blood. 1998;91(1):301-8.
20. Motti PG, Dallabetta GA, Daniel RW, Canner JK, Chiphangwi JD, Liomba GN et al. Cervical abnormalities, human papillomavirus, and human immunodeficiency virus infections in women in Malawi. J Infect Dis. 1996;173(3):714-7.

21. Fedrizzi EN, Laureano JK, Schlup C, Campos MO, Menezes ME. Infecção pelo Papilomavírus Humano (HPV) em mulheres HIV-positivo de Florianópolis, Santa Catarina. DST J Bras Doenças Sex Transm. 2011;23(4):205-9.

22. Lazenby GB. Opportunistic infections in women with HIV AIDS. Clin Obstet Gynecol. 2012;55(4):927-37.

23. Cu-Uvin S, DeLong AK, Ventatesh KK, Hogan JW, Ingersoll J, Kurpewiski J, et al. Genital tract HIV-1 RNA shedding among women with below detectable plasma viral load. AIDS. 2010;24(16):2489-97.

24. Herrera E. Lipid metabolism in pregnancy and its consequence in the fetus and newborn. Endocrine. 2002;19(1):43-55.

25. El Beitune P, Duarte G, Santos JE, Quintana SM, FigueiróFilho EA, Marcolin AC. O uso de anti-retrovirais em gestantes modifica o perfil lipídico? RBGO. 2003;25(8):593-8.

26. Duarte G, Marcolin AC, Quintana SM, Cavalli RC. Infecção urinária na gravidez. Rev Bras Ginecol Obstet. 2008;30(2):93-100.

27. Mussi-Pinhata MM, Quintana SM. Screening for infectious diseases during pregnancy: which test and which situation. Curr Womens Health Rev. 2012;8:158-71. 